\title{
Caroli's disease associated with biliary papillomatosis and cholangiolithiasis
}

A 52-year-old man presented with constant right upper quadrant pain and repeated episodes of fever for 6 months, accompanied with cutaneous and scleral icterus. Laboratory tests suggested a rise in bilirubin. A computed tomography (CT) scan showed obvious dilatation of the intra- and extrahepatic bile ducts, and patchy high density shadows in the intrahepatic bile ducts that were thought to be stones ( $\triangleright$ Fig. 1 ).

Duodenoscopy showed that the orifice of the duodenal papilla was shaped like the mouth of a fish and a large amount of mucus was expelled (>Fig.2). T-tube cholangiography confirmed the dilated hepatic bile ducts ( $\triangleright$ Fig. 3 ). The patient then underwent biliary exploration. During surgery, a large amount of mucus could be seen in the bile duct, and the T-tube was indwelling in the common bile duct. After the surgery, the patient still had abdominal pain, the T-tube drainage was problematic with mucus discharge observed, and there was no significant regression of the jaundice.

The patient underwent cholangioscopy 6 weeks after surgery, which showed diffuse and labyrinth-like dilatation of the intrahepatic bile ducts ( $>$ Fig.4a), which was thought to be Caroli's disease with cholangiolithiasis. Diffuse papillary protrusions could be seen on the intrahepatic bile duct wall, with a large amount

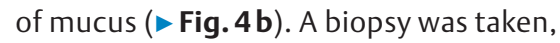
which subsequently confirmed the diagnosis of biliary papillomatosis ( Fig.5). Most of the stones were removed under cholangioscopy ( $\vee$ Video 1 ). After stone extraction, the patient's abdominal pain was relieved and the degree of jaundice gradually decreased.

Caroli's disease is a rare autosomal recessive disorder, which leads to intrahepatic stones and recurrent cholangitis when progressive. It is characterized by a biliary abnormality consisting of segmental saccular dilatations of the large intrahepatic bile ducts [1,2]. Biliary papillomatosis is also a rare disease entity with

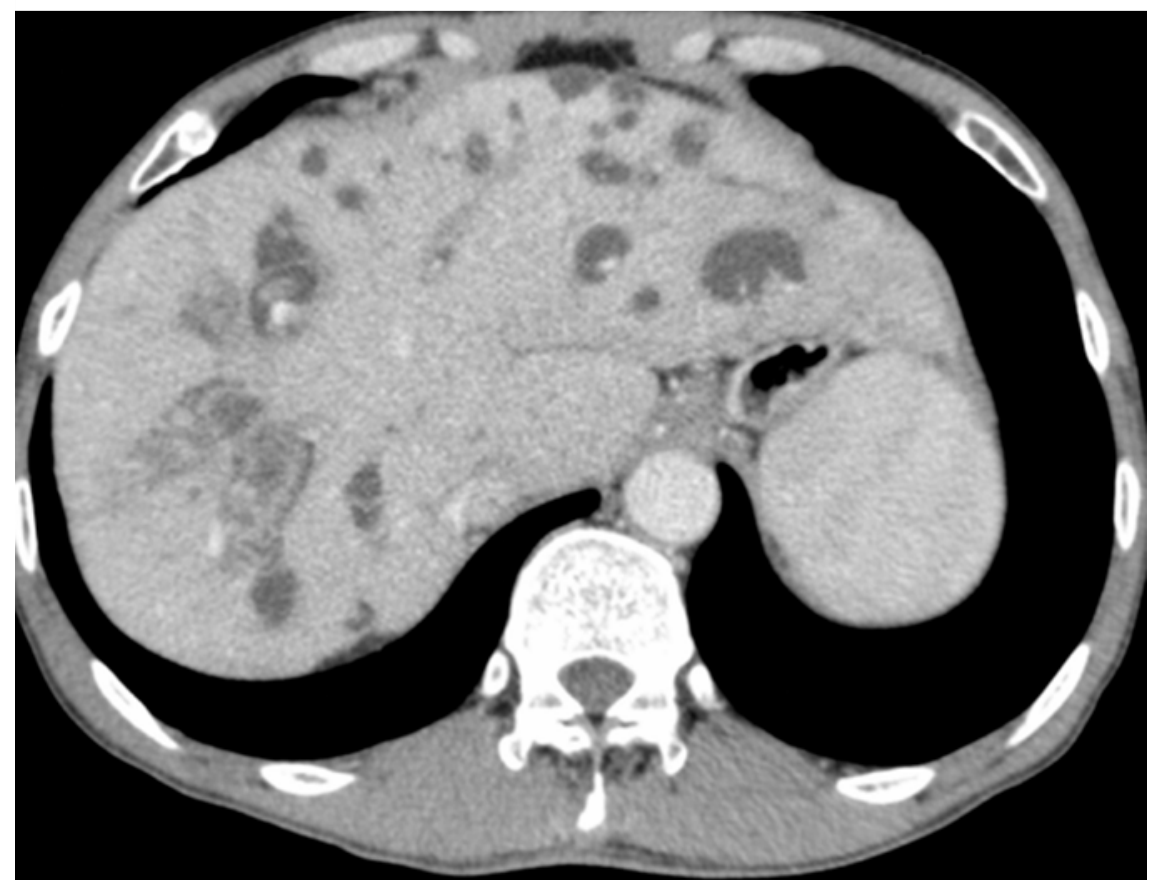

- Fig. 1 Computed tomography scan showing obvious dilatation in the intra- and extrahepatic bile ducts, along with patchy high density shadows in the intrahepatic bile ducts that were thought to be stones.

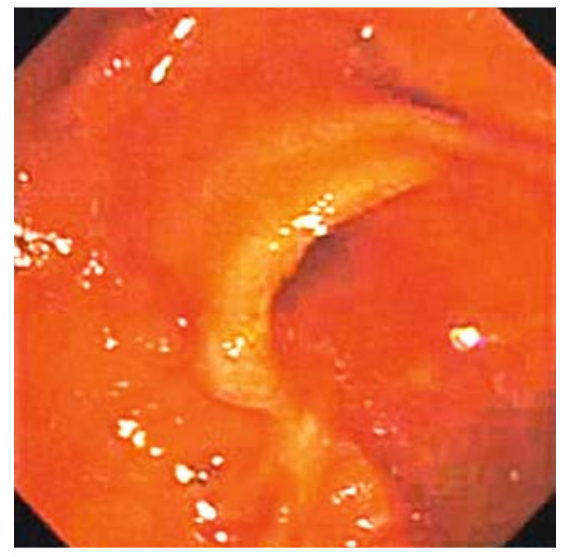

Fig. 2 Duodenoscopy image showing the orifice of the duodenal papilla, which was shaped like the mouth of a fish.

a strong malignant potential, which is characterized by multiple papillary adenomas involving both the intrahepatic and extrahepatic biliary tree [3]. This patient had a wide range of lesions due to papillomas, which could not be comple-

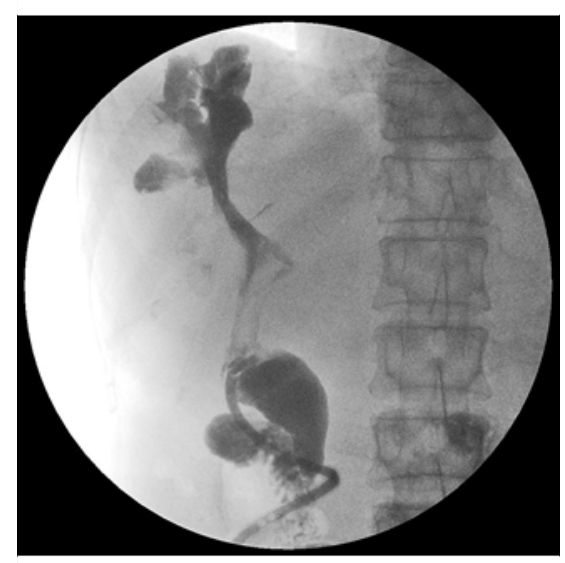

- Fig.3 T-tube cholangiogram showing dilatation of the intra- and extrahepatic bile ducts.

tely resected. The only complete and effective treatment for this condition is liver transplantation [4].

Endoscopy_UCTN_Code_CCL_1AZ_2AZ 


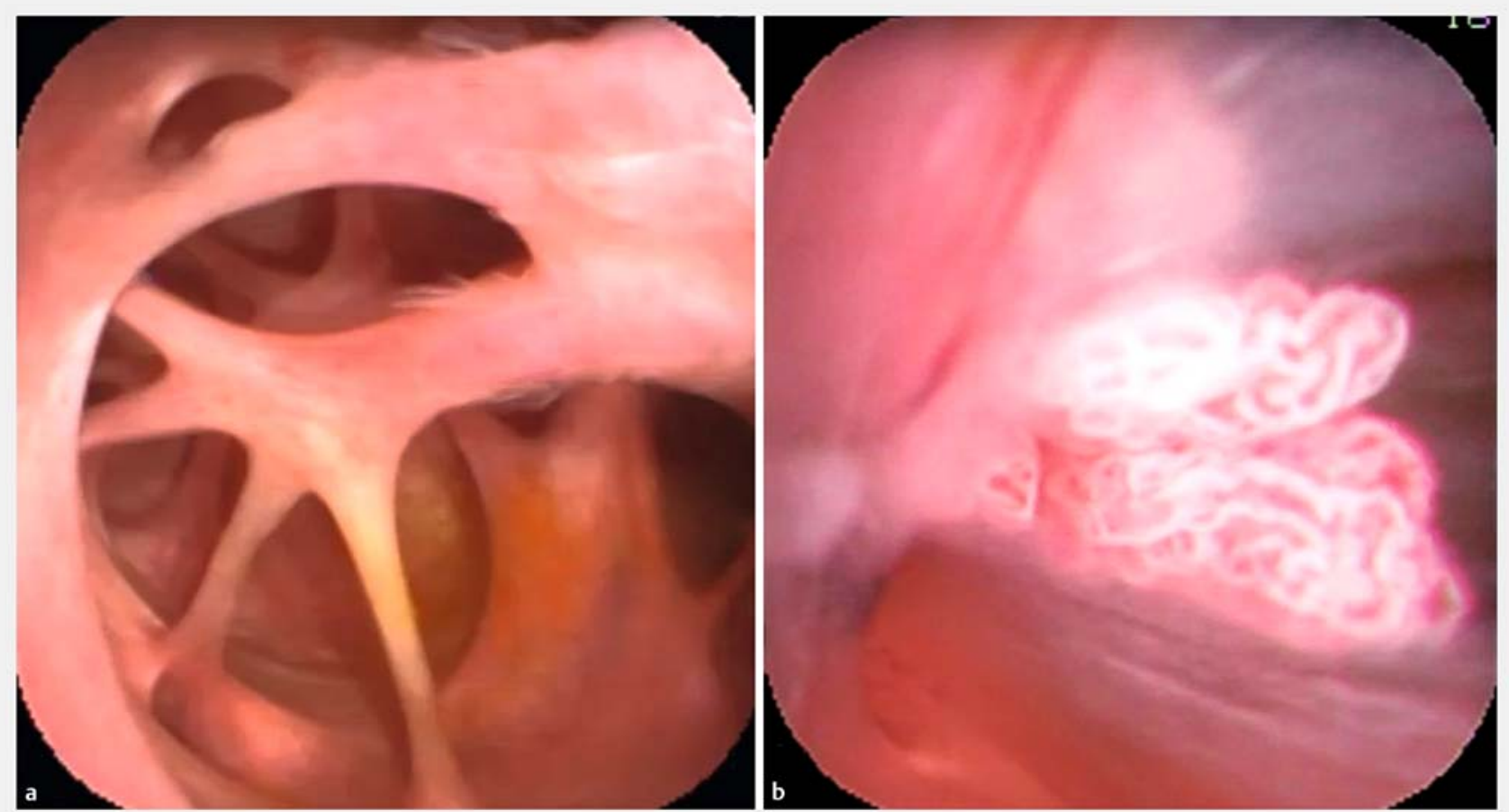

- Fig. 4 Cholangioscopic views showing: a diffuse and labyrinth-like dilatation of the intrahepatic bile duct; $\mathbf{b}$ a large amount of mucus and diffuse papillary protrusions within the intrahepatic bile ducts.

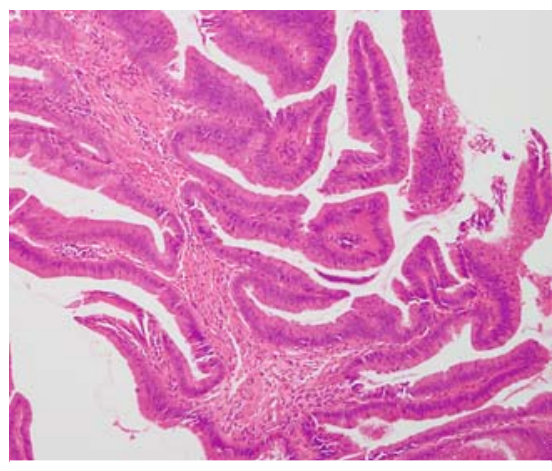

Fig. 5 Histology of the biopsy specimen showing biliary papillomatosis.

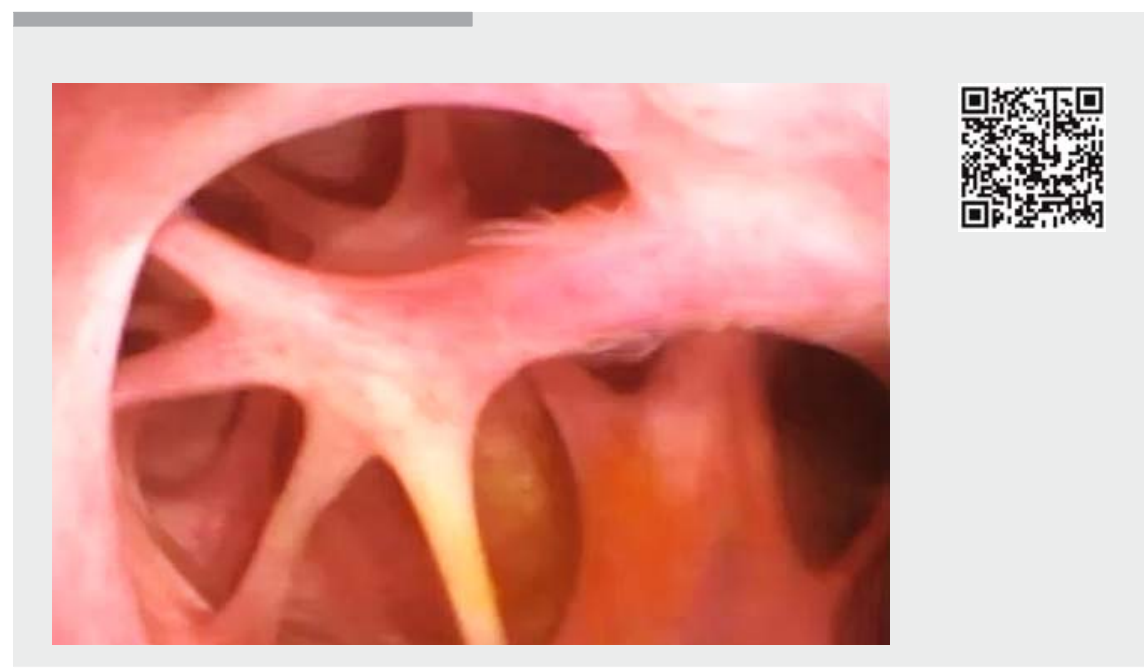

Video 1 Cholangioscopy showing diffuse dilatation of the intrahepatic bile ducts, with a large amount of mucus and cholangiolithiasis. A biopsy is taken and stones are extracted.
Competing interests

None
The authors

Chi Yuan ", Jianrong Liu", Xianghong Zhou, Chuncheng Wu

Department of Gastroenterology, West China Hospital, Sichuan University, Chengdu, China

\footnotetext{
${ }^{*}$ Chi Yuan and jianrong Liu are considered co-first authors of this work.
}

\section{Corresponding author}

\section{Chuncheng Wu, MD}

Department of Gastroenterology, West China Hospital, Sichuan University, No. 37 Guo Xue Alley, Chengdu 610041, Sichuan Province, China

hxwucc@163.com 


\section{References}

[1] Millwala F, Segev DL, Thuluvath PJ. Caroli's disease and outcomes after liver transplantation. Liver Transpl 2008; 14: 11-17

[2] Kassahun WT, Kahn T, Wittekind C et al. Caroli's disease: liver resection and liver transplantation. Experience in 33 patients. Surgery 2005; 138: 888-898

[3] Vassiliou I, Kairivassilatou E, Marinis A et al. Malignant potential of intrahepatic biliary papillomatosis: a case report and review of the literature. World J Surg Oncol 2006; 4: 71
[4] Dumortier J, Scoazec JY, Valette PJ et al. Successful liver transplantation for diffuse biliary papillomatosis. J Hepatol 2001; 35: $542-543$

\section{Bibliography}

DOI https://doi.org/10.1055/a-0640-2859

Published online: 3.7.2018

Endoscopy 2018; 50: E276-E278

(c) Georg Thieme Verlag KG

Stuttgart · New York

ISSN 0013-726X

\section{ENDOSCOPY E-VIDEOS}

https://eref.thieme.de/e-videos

回的 Endoscopy E-Videos is a free access online section, reporting 靣: on interesting cases and new techniques in gastroenterological endoscopy. All papers include a high quality video and all contributions are freely accessible online.

This section has its own submission website at

https://mc.manuscriptcentral.com/e-videos 